\title{
The relationship between cardiovascular disease risk factors and gender
}

\author{
Chung-Min Cho ${ }^{1}$, Young-Mi Lee ${ }^{2 \#}$ \\ ${ }^{1}$ College of Nursing Science, Sungshin Women's University, Seoul, Korea \\ ${ }^{2}$ Department of Nursing, Hanbuk University, Gyeonggi-do, Korea; ${ }^{\sharp}$ Corresponding Author: ymlee@ hanbuk.ac.kr
}

Received 1 February 2012; revised 20 March 2012; accepted 10 April 2012

\begin{abstract}
The purpose of this study was to investigate the relationship between three socioeconomic statuses and five behavior-related cardiovascular risk factors by gender, based on data from the Third Korea National Health and Nutrition Examination III. Data from 4556 people were analyzed. The propensity toward obesity, hypercholesterolemia, and physical inactivity was significantly higher in women than in men. Hypertension and smoking were significantly more prevalent in men than in women. The differences in the prevalence of cardiovascular disease risk factors by gender is important and should be considered when developing programs to reduce the incidence of cardiovascular diseases.
\end{abstract}

Keywords: Cardiovascular Disease; Risk Factor; Gender

\section{INTRODUCTION}

Cardiovascular disease (CVD) is a global health problem and a leading cause of death in developed countries; it is increasing in developing countries [1]. The 3 major causes of death in Korea are cancer, cerebrovascular disease, and cardiac disease. Mortality due to CVD comprised $20 \%$ of the total mortality in 2008 despite public health efforts [2].

CVD is related to lifestyle and individual behavior [3]. Behavioral risk factors such as smoking, hypertension, elevated cholesterol, obesity, and physical inactivity can increase the risk of CVD [4]. Major reductions in CVD risk can be achieved by individual lifestyle and social behavior modifications [5].

CVD is related to socioeconomic status such as education, occupation, income, ethnicity, and place of residence. The Asian study by $\mathrm{Yu}$ also concluded that education

\footnotetext{
"This study is supported through research funds at College of Nursing Science, Sungshin Women's University.
}

seems to be a relatively stronger indicator in evaluating the association between socioeconomic status and cardiovascular risk factor [6]. Winkleby et al. reported that educational level was the only measure of socioeconomic status significantly associated with cardiovascular risk factors in an American population [7]. According to Kaplan and Keil, the principal measures of socioeconomic status have been education, occupation, and income or combinations of these [8]. Considering previous studies, we selected a number of socioeconomic variables including education, poverty level, and occupation for this study.

Gender is also associated with CVD risk, because CVD risk is different in men and women [9]. Although older men and women are equally likely to be in fair or poor health, women are more likely to have difficulty with social and physical activity $[10,11]$. Therefore, gender should be considered in studies of CVD risk factors.

CVD risk factors tend to be synergistic rather than additive [12]. Thus, the assessment of multiple risk factors is crucial to identify a high-risk population. Data on coexistence of these risk factors are scarce, and gender differences in the prevalence of these conditions are unexplored in the Korean population. Few assessments have been carried out to examine the association between socioeconomic status and cardiovascular risk factors in Korea. Data on the relationship between the number of cardiovascular risk factors and socioeconomic status have not previously been reported.

The purpose of this study was to investigate the relationship between three socioeconomic statuses-education, poverty-income ratio (PIR) and occupation-and five behavior-related CVD risk factors-obesity, hypertension, hypercholesterolemia, smoking and physical inactivity by gender.

We analyzed the Third Korea National Health and Nutrition Examination (KNHANES III) data to identify gender differences in the prevalence of individual and coincident CVD risk factors. This study will help in future research and preventive and therapeutic interventions. 


\section{METHODS}

\subsection{Study Design}

We performed a cross-sectional descriptive study using secondary data from KNHANES III, conducted in 2005. The survey utilized multistage stratified clustered probability sampling. The original KNHANES III data included approximately 246,000 primary sampling units, each containing about 60 households (total 14,311,807 households). KNHANES III included 4 surveys: health interview, behavioral, physical examination, and nutriation. A total of 7597 individuals aged 12 years and older participated in these surveys. In this study, survey participants younger than 19 years and older than 65 years were excluded, leaving 4556 health survey participants.

\subsection{Measures}

Data on demographic characteristics and information related to CVD risk factors (body mass index (BMI), blood pressure (BP), non-HDL cholesterol (NHDLC), smoking, physical inactivity) were obtained. Demographics included gender, age, education level, ( $\leq$ high school or zuniversity), and occupation (blue-collar, white-collar, and unemployed). Blue-collar workers included manufacturing workers, farmers, fishermen, mineworkers, salespersons, and soldiers. White-collar workers included managers, professionals, and office workers. Unemployed participants included students, homemakers, and the unemployed. Financial status was categorized using the poverty-income ratio (PIR) - the ratio of family income to the income level deemed minimally adequate for a family of that size for that calendar year (PIR $<1$ indicates impoverishment).

\subsection{Indicators of CVD Risk Factors}

Obesity, hypertension, hypercholesterolemia, smoking, and physical inactivity were defined as major cardiovascular risk factors in previous studies [13]. Obesity was defined as a BMI $\geq 30 \mathrm{~kg} / \mathrm{m}^{2}$. Hypertension was defined as a systolic BP of $\geq 140 \mathrm{mmHg}$ or a diastolic BP of $\geq 90$ $\mathrm{mmHg}$. The initial reading value was used in this study. NHDLC was measured to evaluate hypercholesterolemia. NHDLC is a better indicator of atherogenic lipoprotein particles than the indirectly estimated low-density lipoprotein cholesterol [13]. NHDLC was calculated as the difference between total and HDL cholesterol. Hypercholesterolemia was defined as NHDLC $\geq 190 \mathrm{mg} / \mathrm{Dl}$ [7]. Smoking status was self-reported and defined as currently smoking $>1$ cigarette per week. Physical inactivity was defined as doing almost no physical activity within a given time frame.

\subsection{Statistical Analysis}

All analyses incorporated sampling weights adjusted for unequal sampling probabilities. Results are expressed as means $\pm \mathrm{SD}$ for quantitative variables. Logistic regression analysis was used to determine the odds ratios of CVD risk factors by gender. The number of CVD risk factors was calculated for each subject and analyzed as a discrete variable from 0 (no CVD risk factors) to 5 (all CVD risk factors present), with differences assessed by t-test. $p<0.05$ was considered statistically significant. All statistical analyses were performed by SPSS (v.17.0).

\section{RESULTS}

Figure 1 shows the demographics for 1960 male and 2596 female subjects.

Women were more likely to be less educated and report poorer financial status $(\mathrm{p}<0.001)$ than men, who were more likely to be employed. Blue- and white-collar workers were most prevalent in men and unemployed people were more frequently women $(\mathrm{p}<0.001)$.

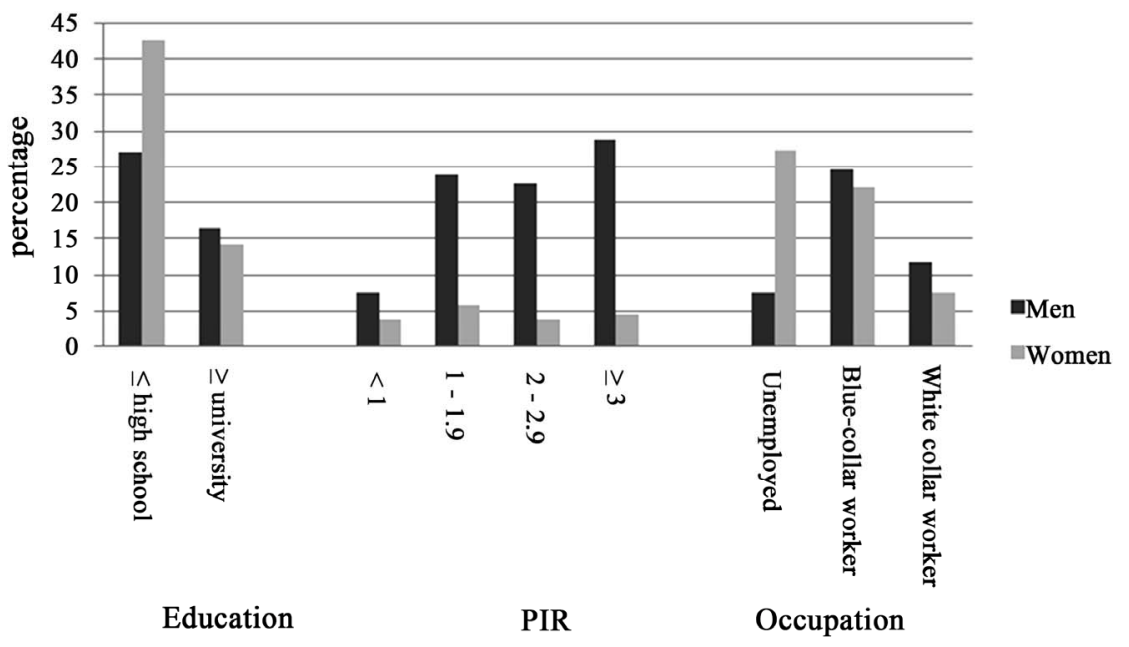

Figure 1. General characteristics among subjects by gender. 
Figure 2 shows the prevalence of cardiovascular risk factors. More women than men presented with obesity $\left(\chi^{2}=175.997, \mathrm{p}<0.001\right)$, hypercholesterolemia $\left(\chi^{2}=\right.$ $176.110, \mathrm{p}<0.001)$, and physical inactivity $\left(\chi^{2}=294.914\right.$, $\mathrm{p}<0.001)$, while more men presented with hypertension $\left(\chi^{2}=446.793, p<0.001\right)$ and smoking $\left(\chi^{2}=393.540, p<\right.$ $0.001)$.

Thirty-five percent of subjects had no cardiovascular risk factors; $60 \%$ subjects had 1 or 2 cardiovascular risk factors. More women had 0 or 1 cardiovascular risk factor, whereas more men had $>2$ (Figure 3 ).

Table 1 shows the mean and SD of anthropometric and physiological conditions by gender. BMI $(t=35.772$, $\mathrm{p}=0.000), \operatorname{SBP}(\mathrm{t}=101.510, \mathrm{p}=0.000)$, DBP $(\mathrm{t}=$ $135.131, \mathrm{p}=0.000)$, and T-C $(\mathrm{t}=8.386, \mathrm{p}=0.000)$ were higher in men than in women. HDL-C $(\mathrm{t}=-119.981, \mathrm{p}=$ 0.000 ) was higher in women.

Table 2 presents the age-adjusted prevalence of CVD risk factors by gender. Men with PIR $<2$ were $>1.2$ times as likely to be obese than those with PIR $\geq 3$. Men and women in the unemployed (men $=\mathrm{OR}, 1.36 ; 95 \% \mathrm{CI}$, $1.12-1.64$, women $=\mathrm{OR}, 5.51 ; 95 \% \mathrm{CI}, 3.81-7.97)$ and blue-collar $($ men $=\mathrm{OR}, 2.20 ; 95 \% \mathrm{CI}, 1.96-2.48$,

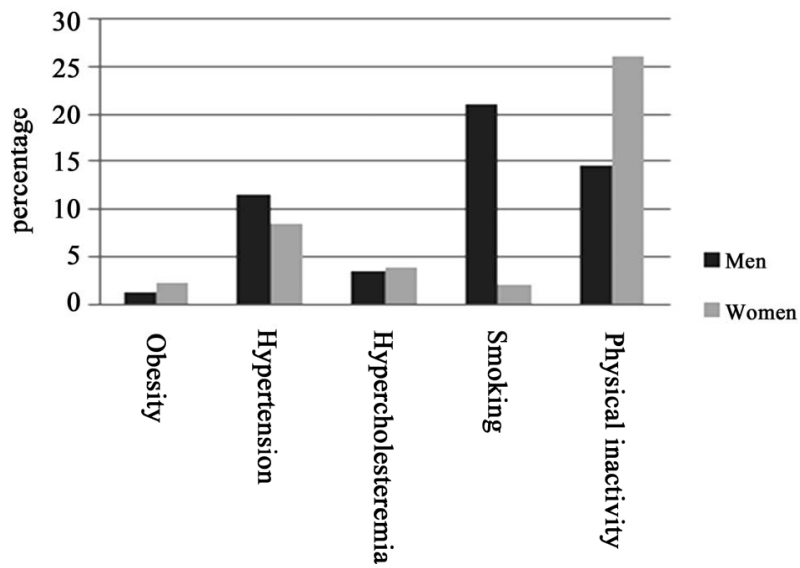

Figure 2. Prevalence of cardiovascular risk factor by gender. women $=$ OR, 2.08; 95\% CI, $1.43-3.05)$ groups were more likely to be obese than white-collar workers. Women with less than high school education were 2.2 times more likely to be obese than those who had more than university education (OR, 2.27; 95\% CI, $1.71-3.00$ ).

The relative risk of hypertension for men with no university education was $8 \%$ greater than for those with university education (OR, 1.08; 95\% CI, 1.04 - 1.13), but in women the opposite was true (OR, 0.68 ; $95 \%$ CI, 0.59 0.79 ). Individuals in the PIR $<1$ group were significantly more likely to have hypertension than those in the $\mathrm{PIR} \geq 3$ group $($ male $=\mathrm{OR}, 1.17 ; 95 \% \mathrm{CI}, 1.10-1.25$, female $=$ OR, $1.66 ; 95 \%$ CI, $1.46-1.88)$. The relative risk of hypertension for the unemployed vs. white-collar workers was 1.3-fold higher in men (OR, 1.34; 95\% CI, $1.26-1.42$ ) and 2.1-fold higher in women (OR, 2.19; $95 \%$ CI, 1.76 - 2.71). The relative risk of hypertension for blue-collar workers was higher-1.2 times in men (OR, 1.24; 95\% CI, $1.19-1.30$ ) and 1.3 times in women (OR, 1.30; 95\% CI, 1.04 - 1.61) - than for white-collar workers. Men and women with no university education were significantly more likely to have hypercholesterolemia than those who did. All men with PIR $<3$ were

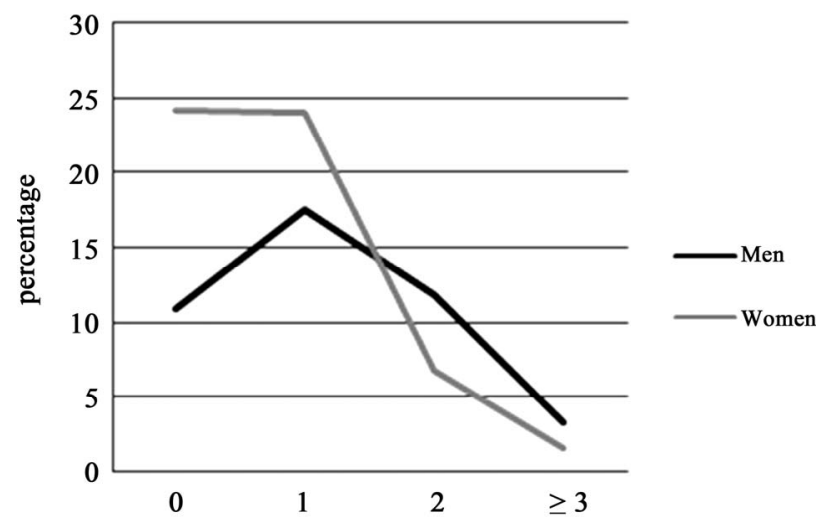

Figure 3. The difference of number of cardiovascular risk factor by gender.

Table 1. The mean and standard deviation of anthropometric and physiological condition by gender.

\begin{tabular}{cccc}
\hline & Men $(\mathrm{n}=1960)$ & Women $(\mathrm{n}=2596)$ & p-value \\
\cline { 2 - 3 } & Mean $\pm \mathrm{SD}$ & Mean $\pm \mathrm{SD}$ & 0.000 \\
\hline Age, $\mathrm{y}$ & $43.0 \pm 11.5$ & $41.9 \pm 11.5$ & 0.000 \\
BMI, $\mathrm{kg} / \mathrm{m}^{2}$ & $24.1 \pm 3.0$ & $23.6 \pm 3.3$ & 0.000 \\
SBP, $\mathrm{mmHg}$ & $123.2 \pm 15.9$ & $116.0 \pm 17.1$ & 0.000 \\
DBP, $\mathrm{mmHg}$ & $81.6 \pm 10.6$ & $75.4 \pm 10.7$ & 0.000 \\
T-C, $\mathrm{mg} / \mathrm{dL}$ & $186.2 \pm 34.9$ & $184.9 \pm 35.5$ & 0.000 \\
HDL-C, $\mathrm{mg} / \mathrm{dL}$ & $42.0 \pm 9.9$ & $47.3 \pm 10.7$ & \\
\hline
\end{tabular}

$\mathrm{BMI}=$ body mass index SBP $=$ systolic blood pressure; $\mathrm{DBP}=$ diastolic blood pressure; $\mathrm{T}-\mathrm{C}=$ total cholesterol; HDL-C $=$ high-density lipoprotein cholesterol. 
Table 2. Odds ratios (OR) and 95\% confidence interval (CI) for the association between general characteristics and cardiovascular risk factors by gender: adjusted for age and other general characteristics.

\begin{tabular}{|c|c|c|c|c|c|c|}
\hline & & Obesity & Hypertension & NHDLC & Smoking & Physical inactivity \\
\hline & & OR $(95 \% \mathrm{CI})$ & OR $(95 \% \mathrm{CI})$ & OR $(95 \% \mathrm{CI})$ & OR $(95 \% \mathrm{CI})$ & OR $(95 \% \mathrm{CI})$ \\
\hline \multicolumn{7}{|c|}{ Men } \\
\hline \multirow[t]{2}{*}{ Education } & $\leq$ high school & $0.77(0.71-0.83)$ & $1.08(1.04-1.13)$ & $1.18(1.11-1.25)$ & $1.25(1.21-1.30)$ & $0.92(0.88-0.95)$ \\
\hline & $\geq$ university & 1 & 1 & 1 & 1 & 1 \\
\hline \multirow[t]{4}{*}{ PIR } & $<1$ & $1.63(1.39-1.91)$ & $1.17(1.10-1.25)$ & $1.84(1.68-2.02)$ & $1.37(1.29-1.45)$ & 1.85 (1.75 - 1.97) \\
\hline & $1-1.9$ & $1.27(1.14-1.41)$ & $0.90(0.87-0.94)$ & $1.15(1.08-1.23)$ & $1.42(1.36-1.47)$ & $1.29(1.24-1.34)$ \\
\hline & $2-2.9$ & $1.05(0.94-1.18)$ & $1.01(0.97-1.05)$ & $1.47(1.38-1.56)$ & $1.04(1.00-1.08)$ & $1.14(1.10$ - 1.19) \\
\hline & $\geq 3$ & 1 & 1 & 1 & 1 & 1 \\
\hline \multirow[t]{3}{*}{ Occupation } & Unemployed & $1.36(1.12-1.64)$ & $1.34(1.26-1.42)$ & $0.56(0.50-0.62)$ & $1.74(1.64-1.84)$ & $1.95(1.84-2.07)$ \\
\hline & Blue-collar & $2.20(1.96-2.48)$ & $1.24(1.19-1.30)$ & $1.00(0.94-1.06)$ & $1.78(1.71-1.85)$ & $0.81(0.78-0.85)$ \\
\hline & White-collar & 1 & 1 & 1 & 1 & 1 \\
\hline \multicolumn{7}{|c|}{ Women } \\
\hline \multirow[t]{2}{*}{ Education } & $\leq$ high school & $2.27(1.71-3.00)$ & $0.68(0.59-0.79)$ & $2.33(1.62-3.34)$ & $0.98(0.88-1.20)$ & $1.28(1.16-1.41)$ \\
\hline & $\geq$ university & 1 & 1 & 1 & 1 & 1 \\
\hline \multirow[t]{4}{*}{ PIR } & $<1$ & $1.06(0.86-1.31)$ & $1.66(1.46-1.88)$ & $0.79(0.63-0.99)$ & $1.01(0.87-1.20)$ & $1.85(1.67-2.04)$ \\
\hline & $1-1.9$ & $1.16(0.96-1.41)$ & $0.85(0.75-0.97)$ & $0.62(0.50-0.78)$ & $1.01(0.87-1.17)$ & $0.64(0.59-0.71)$ \\
\hline & $2-2.9$ & $0.42(0.33-0.55)$ & $1.08(0.95-1.24)$ & $1.41(1.13-1.75)$ & $0.69(0.58-0.82)$ & $1.15(1.04-1.27)$ \\
\hline & $\geq 3$ & 1 & 1 & 1 & 1 & 1 \\
\hline \multirow[t]{3}{*}{ Occupation } & Unemployed & $5.51(3.81-7.97)$ & $2.19(1.76-2.71)$ & $0.98(0.66-1.44)$ & $2.65(1.94-3.63)$ & $1.48(1.32$ - 1.67) \\
\hline & Blue-collar & $2.08(1.43-3.05)$ & $1.30(1.04-1.61)$ & $0.74(0.51-1.09)$ & $6.65(4.90-9.03)$ & $0.64(0.57-0.72)$ \\
\hline & White-collar & 1 & 1 & 1 & 1 & 1 \\
\hline
\end{tabular}

significantly more likely to have hypercholesterolemia than men with PIR $\geq 3$. Women with PIR 2 - 2.9 were 1.4 times more likely to have hypercholesterolemia than those with PIR $\geq 3$ (OR, 1.41; 95\% CI, 1.13 - 1.75). In general, smoking was more prevalent in men than in women. However, unemployed and blue-collar women were more likely to be smokers than men. Women without university education were 1.2 times more likely to be physically inactive than those with university education (OR, 1.28; 95\% CI, 1.16 - 1.41). All men with PIR < 3 were significantly more likely to be physically inactive than those with PIR $\geq 3$. Women with PIR of $<1$ and 2 2.9 were more likely to be physically inactive than those with $\mathrm{PIR} \geq 3$. Unemployed individuals were more likely to be physically inactive than white-collar workers (men $=\mathrm{OR}, 1.95 ; 95 \% \mathrm{CI}, 1.84-2.07$, women $=\mathrm{OR}, 1.48$; 
95\% CI, 1.32 - 1.67).

Table 3 shows gender differences in the number of cardiovascular risk factors. For both genders, groups with less education, lower financial status, and unemployment had a significantly higher number of cardiovascular risk factors. The number of cardiovascular risk factors was significantly different between men and women $(p=0.000)$.

\section{DISCUSSION}

Behaviors such as smoking, unhealthy diet, and physical inactivity are associated with CVD [14]. Socioeconomic status is also likely associated with behavioral risk factors because persons of lower socioeconomic status confront more barriers to modifying risk behaviors over time, such as quitting smoking, improving diet, and increasing physical activity [15]. It is important to encourage healthy lifestyle changes to reduce the prevalence of CVD. Consistent with previous studies of gender differences in cardiovascular risk [16,17], we found associations between education, occupation, and financial status and cardiovascular risk factors. Such differences may be due to underlying gender differences in biological vulnerability; social coping mechanisms; and access to material, social, and physiological resources [18].

Our study showed that men have higher levels of education, higher economic status, and higher employment rates than women. More men presented with hypertension and smoking, and more women presented with obesity, hypercholesterolemia, and physical inactivity. Except for hypercholesterolemia, these results were similar to those of studies conducted in Canada, the US, and China $[4,6,19]$. The results of previous study for hypercholesterolemia mainly focus on the average values of cholesterol when comparing men and women [20]. They reported that men have more elevated cholesterol levels than women. They are careful to note that men are in need of cholesterol management. In our study, however, the proportion of hypercholesterolemia (NHDLC $\geq 190$ ) for men was than for women. These results imply that women can be vulnerable as well, and are in need of adequate health care in response.

Obesity in men was significantly associated with low income and occupation. Obesity in women was significantly associated with low income and education. Gender difference for obesity was consistent with previous study findings. Harrell and Gore found that low education was a significant predictor of obesity, but in women, low income was not [21]. Yu et al. found that occupation and income were significantly related to obesity in men [6].

Our results show that blue-collar men had higher BMI than white-collar employees and unemployed men. Unemployed women had higher BMI than employed women. This study shows that the major predictor of obesity was occupational status in both men and women, especially in women. Therefore, we suggest that an occupational approach may be effective for obesity and CVD prevention.

Numerous studies indicate that there is an inverse relationship between socioeconomic status and hypertension. Sorel et al. [22] reported that a statistically significant inverse relationship between educational level and high blood pressure was present in their studies. A study conducted in Australia reported that hypertension is inversely associated with socioeconomic status both in men and women [23]. In a study in Norway, age-adjusted mean systolic and diastolic blood pressures were inversely associated with socioeconomic status in women [24]. However, in a study conducted in Germany, the prevalence of hypertension was inversely related to socioeconomic status in women but not in men [25]. Our study found that the relative risk of hypertension was inversely related to socioeconomic status with the exception of education level in women. There was no clear association between each variable of socioeconomic status and hypertension by gender. More research in needed for clear results.

Table 3. Difference in the number of cardiovascular risk factors according to general characteristics by gender.

\begin{tabular}{|c|c|c|c|c|c|}
\hline & & \multicolumn{2}{|c|}{ Men } & \multicolumn{2}{|c|}{ Women } \\
\hline & & Mean \pm SD & $\mathrm{p}$-value & Mean \pm SD & $\mathrm{p}$-value \\
\hline Education & $\leq$ high school ${ }^{*}$ & $1.26 \pm 0.92$ & 0.000 & $0.84 \pm 0.82$ & 0.000 \\
\hline level & $\geq$ university $^{*}$ & $1.05 \pm 0.88$ & & $0.49 \pm 0.59$ & \\
\hline \multirow[t]{4}{*}{ PIR } & $<1^{*}$ & $1.53 \pm 0.93^{\mathrm{a}}$ & 0.000 & $1.20 \pm 0.90^{\mathrm{a}}$ & 0.000 \\
\hline & $1-1.9^{*}$ & $1.28 \pm 0.91^{\mathrm{b}}$ & & $0.78 \pm 0.87^{\mathrm{b}}$ & \\
\hline & $2-2.9^{*}$ & $1.17 \pm 0.91^{\mathrm{c}}$ & & $0.93 \pm 0.70^{c}$ & \\
\hline & $\geq 3^{*}$ & $1.06 \pm 0.92^{\mathrm{d}}$ & & $0.73 \pm 0.75^{b}$ & \\
\hline \multirow[t]{3}{*}{ Occupation } & Unemployed* & $1.30 \pm 0.92^{\mathrm{a}}$ & 0.000 & $0.78 \pm 0.82^{\mathrm{a}}$ & 0.000 \\
\hline & Blue-collar ${ }^{*}$ & $1.23 \pm 0.91^{b}$ & & $0.78 \pm 0.77^{\mathrm{a}}$ & \\
\hline & White collar $^{*}$ & $1.00 \pm 0.87^{\mathrm{c}}$ & & $0.53 \pm 0.61^{\mathrm{b}}$ & \\
\hline
\end{tabular}

${ }^{*} \mathrm{p}=0.000$ between men and women by t-test; ${ }^{\mathrm{a}, \mathrm{b}, \mathrm{c}, \mathrm{d}}$ significant difference by the Scheffe test. 
In both genders, the relative risk of hypercholesterolemia of people who didn't have secondary education was higher than those who did. The result was the same as that of Choiniere et al. [4]. They said that men and women with a university degree were less likely to have elevated cholesterol levels than those with no university degree.

Socioeconomic status in inversely associated with smoking in men and with physical inactivity in women. Unemployed and blue-collar employees have higher rates of smoking than white-collar employees. The relative risk of smoking for blue-collar employees was higher than for unemployed people. These results were consistent with previous studies. In Kaplan and Keil's reports, white-collar men had rates of smoking $13.7 \%$ lower than blue collar men. For women, the difference was $5.9 \%$.

They found that smoking prevalence is related to employment status, income, and other measures of socioeconomic status, with lower rates of smoking associated with employment and higher socioeconomic status [8]. Smoking is the single most preventable cause of premature death [4]. Our findings show that smoking prevalence rates vary greatly with occupational status in women. The relative risk of smoking in blue-collar workers was higher than in unemployed and white-collar workers. These results were consistent with those from a previous study [26]. Smoking prevention campaigns may be useful not only for the subgroup that is addressed, but also for fellow workers. Subjects who stopped smoking may induce fellow workers to reduce tobacco consumption. On the other hand, smoking restriction at the workplace might be associated with lower smoking rates.

The overall prevalence of multiple CVD risk factors was significantly greater in men than in women and was significantly associated with low education level, income, and occupation status. The gender-specific prevalence rates were consistent with previously reported findings in European countries [4].

Alkerwi et al. reported that men are at greater risk for CVD than women, and this difference increases in magnitude with advancing age [5]. Moreover, multiple risk profiles emerge within young adults aged 18 - 29 years.

This is the first detailed report on the coexistence of CVD risk factors in a nationally representative Korean population. We found that men have a greater quantity of CVD risk factors but relative risk for cardiovascular disease is higher in women. Cardiovascular risk factors and relative according to socioeconomic status were different according to gender. These results were consistent with results of Karlamangla et al. who reported that the associations between socioeconomic status and CVD risk accumulation were stronger in women than in men [27]. Gender should be considered when health professionals make recommendations for behavior modification to reduce the CVD risk of their patients because health behaviors are different by gender.

Education, income, and occupation are interrelated [28]. Less-educated groups are more likely to have lowerpaying jobs, such as those that require manual labor. Although education was a strong predictor of obesity for women, this association was not apparent in men. The reason for this is unclear and requires further study.

The high burden of multiple CVD risk factors in poorly educated, low-income, and unemployed men and women means that it is important to target this vulnerable segment of the population for CVD prevention programs in Korea. Studies show that increased life expectancy that arises from changes in the prevalence of CVD risk factors is more substantial in at-risk individuals than in the whole population. These facts should be considered when planning CVD intervention programs.

Gender should be considered when health professionals recommend behavior modification to reduce the cardiovascular risk of their patients because health behaveiors differ by gender [17].

This study had some limitations. We used a cross-sectional design, which did not allow for the determination of concrete causal relationships over a specific time interval. Despite these limitations, this study provides important data on the prevalence of gender-specific CVD risk factors among adults in South Korea.

\section{REFERENCES}

[1] Ueshima, H., Sekikawa, A., Miura, K., Turin, T.C., Tafashima, N., Kita, Y., Watanabe, M., Kadota, A., Okuda, N., Kadowaki, T., Nakamura, Y. and Okamura, T. (2008) Cardiovascular disease and risk factors in Asia: A selected review. Circulation, 118, 2702-2709. doi:10.1161/CIRCULATIONAHA.108.790048

[2] Korean Statistical Information Service (2007) 2006 Mortality and causes of death.

http://kostat.go.kr/nso main/nsoMainAction.do?method= search\&catgrp $=$ nso $2009 \&$ catid $1=k 09 \quad 0000 \&$ catid $2=k$ 09i 0000\&forward=search

[3] Greenlund, K.J., Zheng, Z.J., Keenan, N.L., Giles, W.H., Casper, M.L., Mensah, G.A. and Croft, J.B. (2004) Trends in self-reported multiple cardiovascular disease risk factors among adults in the United States, 1991-1999. Archives of Internal Medicine, 164, 181-188. doi:10.1001/archinte.164.2.181

[4] Choiniere, R., Lafontaine, P. and Edwards, A.C. (2000) Distribution of cardiovascular disease risk factors by socioeconomic status among Canadian adults. Canadian Medical Association Journal, 162, s13-s19.

[5] Alkerwi, A., Sauvageot, N., Donneau, A.F., Lair, M.L., Couffignal, S., Beissel, J., Delagardelle, C., Wagner, Y., Albert, A. and Guillaume, M. (2010) First nationwide survey on cardiovascular factors in Grand-Duchy of Lux- 
embourg. BMC Public Health, 10, 468. doi:10.1186/1471-2458-10-468

[6] Yu, Z., Nissinen, A., Vartiainen, E., Song, G., Guo, Z., Zheng, G., Tuomilehto, J. and Tian, H. (2000) Associations between socioeconomic status and cardiovascular risk factors in an urban population in China. Bulletin of the World Health Organization, 78, 1296-1305.

[7] Winkleby, M.A., Robinson, T.N., Sundquist, J. and Kraemer, H.C. (1999) Ethnic variation in cardiovascular disease risk factors among children and young adults. Journal of the American Medical Association, 281, 10061013. doi:10.1001/jama.281.11.1006

[8] Kaplan, G.A. and Keil, J.E. (1993) Socioeconomic factors and cardiovascular disease: A review of the literature. Circulation, 88, 1973-1998.

[9] Park, H.S., Shin, H.C., Kim, B.S., Lee, K.Y., Choi, W.S., Shin, J.A., Nam, Y.D., Bae, S.P. and Chun, K.S. (2003) Prevalence and associated factors of metabolic syndrome among adults in primary care. The Korean Journal of Obesity, 12, 108-123.

[10] Ferrara, C.M., Lynch, N.A., Nicklas, B.J., Ryan, A.S. and Berman, D.M. (2002) Differences in adipose tissue metabolism between postmenopausal and perimenopausal women. Journal of Clinical Endocrinology \& Metabolism, 87, 4166-4170. doi:10.1210/jc.2001-012034

[11] Nassis, G.P. and Geladas, N.D. (2003) Age-related pattern in body composition changes for 18- to 69-year old women. Journal of Sports Medicine and Physical Fitness, 43, 327-333.

[12] Chu, N.F., Rimm, E.B., Wang, D.J., Lious, H.S. and Shieh, S.M. (1998) Clustering of cardiovascular disease risk factors among obese schoolchildren: The Taipei Children Heart Study. The American Journal of Clinical Nutrition, 67, 1141-1146.

[13] Ybarra, J., Sanchez-Hernandez, J. and Perez, A. (2005) Non-HDL-cholesterol, waist circumference and the HOMA index: Correlations in the healthy. Prevention and Control, 1, 183-184. doi:10.1016/j.precon.2005.05.002

[14] Bae, S., Urrutia-Rojas, X., Patel, D., Migala, W.M., Rivers, P.A. and Singh, K.P. (2007) Comparison of health behaviors among single- and multiple-member households. American Journal of Health Behavior, 31, 514-525. doi:10.5993/AJHB.31.5.7

[15] Tancredi, D. and Frscella, K. (2008) Socioeconomic status and coronary heart disease risk prediction. Journal of the American Medical Association, 300, 2666-2668. doi:10.1001/jama.2008.792

[16] Molarius, A., Siedell, J.C., Sans, S., Tuomilehto, J. and Kuulasamaa, K. (2000) Educational level, relative body weight, and changes in their association over 10 years: An international perspective from the WHO Monica Project. American Journal of Public Health, 90, 1260-1268. doi:10.2105/AJPH.90.8.1260

[17] Wardle, J., Maller, J. and Jarvis, M.J. (2002) Sex differences in the association of socioeconomic status with obesity. American Journal of Public Health, 92, 12991304. doi:10.2105/AJPH.92.8.1299
[18] MacIntyre, S. and Hunt, K. (1997) Socio-economic position, gender, and health: How do they interact? Journal of Health Psychology, 2, 315-334. doi: $10.1177 / 135910539700200304$

[19] D'Agostino, R.B., Vasan, R.S., Pencina, M.J., Wolf, P.A., Cobain, M., Massaro, J.M. and Kannel, W.B. (2008) General cardiovascular risk profile for use in primary care: The Framingham heart study. Circulation, 117, 743-753. doi:10.1161/CIRCULATIONAHA.107.699579

[20] Kivimaki, M., Smith, G.D., Juonala, M., Ferrie, J.E., Keltikangas-Jarvinen, L., Elovainio, M., Pulkki-Raback, L., Vahtera, J., Leino, M., Viikari, J.S.A., and Raitakari, O.T. (2006) Socioeconomic position in childhood and adult cardiovascular risk factors, vascular structure, and function: Cardiovascular risk in young Finns study. Heart, 92, 474-480. doi:10.1136/hrt.2005.067108

[21] Harrell, J.S. and Gore, S.V. (1998) Cardiovascular risk factors and socioeconomic status in African American and Caucasian women. Research in Nursing \& Health, 21, 285-295.

doi:10.1002/(SICI)1098-240X(199808)21:4<285::AID-N UR2>3.0.CO;2-B

[22] Sorel, J.E., Ragland, D.R, syme, S.L. and Davis, W.B. (1992) Educational status and blood pressure: The second national health and nutrition examination survey, 19761980, and the Hispanic health and nutrition examination survey, 1982-1984. American Journal of Epidemiology, 135, 1339-1348.

[23] Bennett, S. (1995) Cardiovascular risk factors in Australia: Trends in socioeconomic inequalities. Journal of Epidemiology and Community Health, 49, 363-372. doi:10.1136/jech.49.4.363

[24] Jacobsen, B.K. and Thelle, D.S. (1988) Risk factors for coronary heart disease and level of education: The Tromso heart study. American Journal of Epidemiology, 127, 923 932.

[25] Helmert, U., Herma, B., Joeckel, K.H., Greiser, E. and Madans, J. (1989) Social class and risk factors for coronary heart disease in the Federal Republic of Germany. Results of the baseline survey of the German Cardiovascular Prevention Study (GCP). Journal of Epidemiology and Community Health, 43, 37-42. doi:10.1136/jech.43.1.37

[26] Hermert, U., Shea, S., Herman, B. and Greiser, E. (1990) Relationship of social class characteristics and risk factors for coronary heart disease in West Germany. Public Health, 104, 399-416. doi:10.1016/S0033-3506(05)80083-6

[27] Karlamangla, A.S., Singer, B.H., Williams, D.R., Shwartz, J.E., Matthews, K.A., Kiefe, C.I. and Seeman, T.E. (2004) Impact of socioeconomic status on longitudinal accumulation of cardiovascular risk in young adults: The CARDIA study. Social Science \& Medicine, 60, 999-1015. doi:10.1016/j.socscimed.2004.06.056

[28] Ham, O.K. (2007) Psychosocial factors associated with lifetime experience of serious uintentional injury in South Korea. Public Health Nursing, 25, 37-45. doi:10.1111/j.1525-1446.2008.00678.x 